\title{
Obscure gastrointestinal bleeding from an ampullary tumour in a patient with a remote history of renal cell carcinoma: A diagnostic conundrum
}

Rhonda M Janzen MD, Alnoor S Ramj BScPharm, Julia DA Flint MB ChB FRCPC, Charles H Scudamore MD FRCSC, Eric M Yoshida MD FRCPC

RM Janzen, AS Ramj, JDA Flint, CH Scudamore, EM Yoshida. Obscure gastrointestinal bleeding from an ampullary tumour in a patient with a remote history of renal cell carcinoma: A diagnostic conundrum. Can J Gastroenterol 1998;12(1):75-78. Metastasis of renal cell carcinoma to the ampulla of Vater is a rare occurrence. The outlined case, which presented as an upper gastrointestinal bleed, is only the eighth such reported case in the English-language literature. This case is the longest reported time interval between surgical nephrectomy to presentation with ampullary metastasis at 17.5 years. The ampullary source of bleeding in this case was initially obscure and missed by conventional gastroscopy. Diagnosis was made with a side-viewing endoscope, emphasizing the usefulness of this instrument in the investigation of active bleeding from a small bowel source.

Key Words: Ampulla, Gastrointestinal bleed, Metastatic, Periampullary renal cell carcinoma, Renal cell carcinoma

\section{Saignement gastro-intestinal obscur d'une} tumeur ampullaire chez un patient présentant des antécédents lointains de cancer du rein : méandre diagnostique

RÉSUMÉ : Les métastases du cancer du rein vers l'ampoule de Vater sont un phénomène rare. Le cas présenté ici, soit un saignement des voies digestives supérieures, n'est que le huitième du genre signalé dans la littérature de langue anglaise. Il s'agit du plus long intervalle entre la néphrectomie et l'apparition de la métastase ampullaire, après 17 ans et demi. La source ampullaire de l'hémorragie dans ce cas a été difficile à identifier et n'a pu être décelée par gastroscopie classique. Le diagnostic a été posé au moyen d'un endoscope à vue latérale, ce qui souligne l'utilité de cet instrument pour le diagnostic de l'hémorragie active du petit intestin.
$\mathrm{I}$ dentifying an upper gastrointestinal bleed from a small bowel source is often difficult and frustrating. The source of bleeding is usually beyond the reach of the conventional gastroscope and far proximal to the maximal extent of ileoscopy with a conventional colonoscope. Endoscopic op- tions include enteroscopy with a pediatric colonoscope or 'Sonde-type' enteroscopy (1), which is not readily available in most centres. Radionuclide tagged red blood cell scans and angiography will only be of value during active bleeding and may appear to produce a false negative result if the active

Departments of Medicine, Surgery, and Anatomical Pathology; and School of Medicine, University of British Columbia, Vancouver, British Columbia

Correspondence: Dr EM Yoshida, Division of Gastroenterology, Vancouver Hospital Ë Health Sciences Centre, 3300-950 West 10th Avenue, Vancouver, British Columbia V5Z 4E3. Telephone 604-875-5862, fax 604-875-5447

Received for publication October 16, 1997. Accepted December 12, 1997 


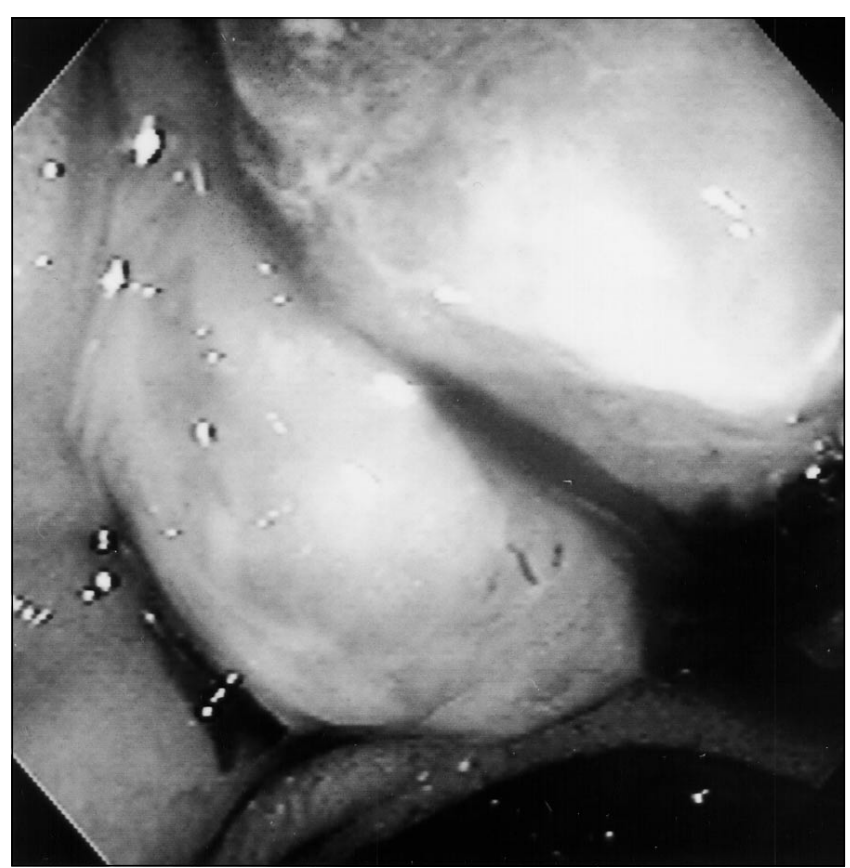

Figure 1) Photograph of metastatic periampullary renal cell carcinoma taken with a video side-viewing endoscope (Olympus JFI30; Olympus Inc, Tokyo, Japan). The periampullary mass had been missed on repeated upper endoscopy with a conventional end-viewing gastroscope

bleeding is only intermittent. Conventional radiographic imaging techniques to search for mucosal abnormalities, such as the small bowel follow-through study and enteroclysis, may not be practical options in hemodynamically unstable acutely bleeding patients.

We present a patient who presented with recurring upper gastrointestinal bleeding from a periampullary metastatic renal cell carcinoma many years after surgical resection. This case is clinically interesting for several reasons. From the diagnostic standpoint, it illustrates the challenge of the obscure upper gastrointestinal bleed. Furthermore, this case is only the eighth case of a periampullary renal cell cancer to be reported in the English language (2-7). This case also comprises the longest reported interval of renal cell carcinoma metastasis at this site after primary surgical 'cure'.

\section{CASE PRESENTATION}

A 75-year-old Caucasian man presented with a $24 \mathrm{~h}$ history of passing maroon-coloured stools and an initial hemoglobin of $53 \mathrm{~g} / \mathrm{L}$ (normal 133 to $175 \mathrm{~g} / \mathrm{L}$ ). Five weeks previously he had been hospitalized after a similar presentation. During that hospitalization, an emergency gastroscopy revealed esophagitis grade II/IV (8). A follow-up upper endoscopy revealed evidence of a Mallory-Weiss tear.

Past medical history revealed that 17.5 years previously the patient had undergone a left total nephrectomy for renal cell carcinoma. No adjuvant radiation or chemotherapy had been administered, and the malignancy was regarded as being surgically cured with no evidence of recurrence. Other concurrent medical problems included chronic renal failure

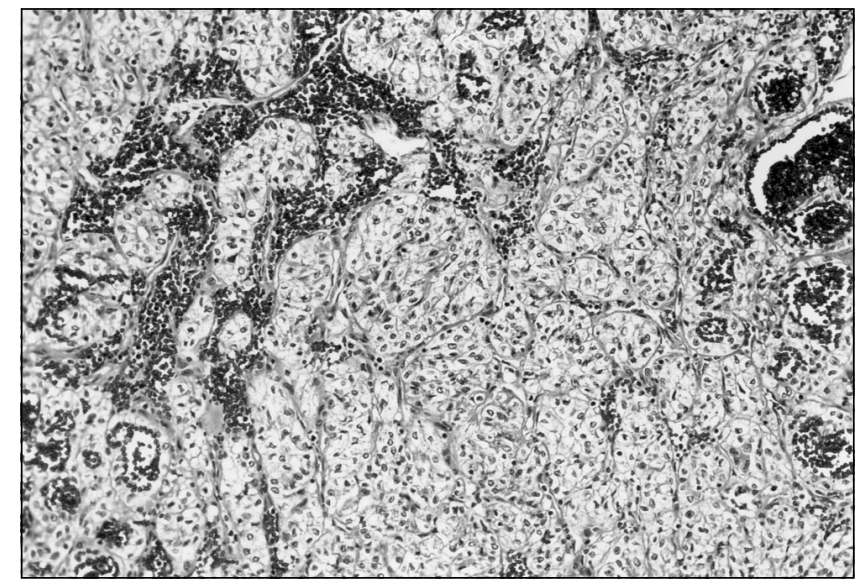

Figure 2) High power view of the metastatic renal cell carcinoma, clear cell type. Note the vascular nature of the tumour (hematoxylin and eosin stain)

with a serum creatinine of $335 \mu \mathrm{mol} / \mathrm{L}$ (normal less than $135 \mu \mathrm{mol} / \mathrm{L})$.

After the patient was resuscitated with intravenous fluids and transfusion of packed red blood cells, upper endoscopy was once again performed. Endoscopy revealed a substantial volume of blood in the fundus. There was a clot on the anterior wall of the stomach near the greater curvature. There was no other evidence of ulceration, and duodenoscopy into the second and third parts of the duodenum revealed only some pooled blood. Following the gastroscopy, a tagged-red cell radionuclide scan was performed. No active bleeding was seen until after 180 mins, when the patient vomited. The source of bleeding appeared to be either the stomach or the jejunum.

The patient was returned to the endoscopy suite and the gastroscopy repeated. This time no evidence of clot was seen in the stomach. Passage of the gastroscope into the duodenum gave the impression of a possible mass in the periampullary area. An endoplasmic retrograde cholangiopancreatographic (ERCP), side-viewing endoscope was then intubated into the upper gastrointestinal tract. By using a short-scope technique, the ampullary region was well-visualized. A large periampullary tumour was clearly seen (Figure 1).

A magnetic resonance imaging scan was then obtained, which revealed a $5 \mathrm{~cm}$ periampullary mass extending into the head of the pancreas. The liver was unremarkable, but two lesions were noted in the spleen. The patient was taken to surgery, and a total pancreatectomy, duodenectomy with cholecystectomy and splenectomy were performed.

Histologic examination of the resected specimen showed metastatic renal cell carcinoma of the clear cell type (Figure 2 ) involving the full thickness of the duodenal wall without extension into the pancreas or the pancreatic duct. Incidental findings included a cystic mucinous pancreatic tumour that was of borderline malignant potential and an epithelioid hemangioendothelioma of the spleen.

The patent was eventually discharged home after a protracted period of convalescence. 


\section{DISCUSSION}

Renal cell carcinoma comprises only $2 \%$ of all cancers (9). The treatment of localized tumours is surgical nephrectomy. Even with a surgical resection with curative intent, $20 \%$ to $30 \%$ of these tumours will recur (9). The site of recurrence is typically distant from the original nephrectomy site, usually the lung, liver, bone or brain (10). Less common sites of metastasis include the gallbladder, urinary bladder and corpus cavernosum (10). Tumour recurrence most often occurs within three years of the initial nephrectomy (10), and the longer the recurrence-free period from the time of surgery, the better the likelihood of true surgical cure.

Isolated solitary renal cell carcinoma metastases are uncommon, with an incidence of approximately $1 \%$ to $2 \%$ (10). Surgical resection of these solitary metastases is associated with a five-year survival of $35 \%$ (10). Renal cell carcinoma metastases presenting as periampullary masses indistinguishable endoscopically from primary ampullary carcinomas - are decidedly rare. To our knowledge, our patient is only the eighth reported case in the English language literature of renal cell carcinoma to present as a periampullary tumour. From the eight previously reported cases (2-7) and from our own case, it appears that the primary renal cell carcinoma is typically left-sided (2-6), with men predominantly affected $(2,3,5,6)$. The primary renal cancer stages of these cases were evenly divided between stages 1 and 3 before periampullary presentation (Table 1) (11). The majority of cases, including ours, presented with a gastrointestinal bleed $(2,3,5)$. Other reported presenting symptoms included jaundice (4) and malabsorption (6). The interval between original nephrectomy and periampullary presentation is typically long, median 10 years (range one to 12 years) (2-6). Our patient presented 17 years and six months after the original nephrectomy, which is the longest interval period yet reported, illustrating the insidious nature of these neoplasms.

Metastatic tumours to the periampullary region are very rare as are metastases to the upper gastrointestinal tract in general (12). A recent review series from Johns Hopkins University of 239 pancreaticoduodenectomies for malignant disease found only six periampullary metastatic cancers (2.5\%): one each of renal cell carcinoma, squamous lung cancer, small cell lung cancer and breast cancer, and two colonic cancers (7). Surgical options in the treatment of metastatic periampullary metastatic carcinomas include pancreaticoduodenectomy (13) - the standard surgical treatment for primary ampullary carcinomas - and, in one report, posthormonal (megestrol acetate) pancreatectomy (3). Despite the report of success with adjuvant hormonal therapy in this one case, conventional chemotherapy and hormonal agents have little effect on renal cell carcinoma (14). Similarly, the effect of biological immune modifying agents (eg,

\section{REFERENCES}

1. Cotton PB, Williams CB. Small intestinal endoscopy. In: Practical Gastrointestinal Endoscopy, 3rd edn. London: Blackwell Scientific Publications, 1990:157-9.

2. Leslie KA, Tsao JI, Rossi RL, Braasch JW. Metastatic renal cell carcinoma to ampulla of Vater: An unusual lesion amenable to surgical resection. Surgery 1996;119:349-51.
TABLE 1

Modified Robson staging system for renal cell cancer

\begin{tabular}{ll}
\hline Stage & Extent of cancer \\
\hline 1 & Confined to renal capsule \\
2 & Through capsule, confined to Gerota's fascia \\
3 & $\begin{array}{c}\text { Renal vein or vena cava involvement and/or regional } \\
\text { node involvement }\end{array}$ \\
4 & Direct organ invasion or distant metastases \\
\hline
\end{tabular}

Data based on reference 11

interferon), which have been reported to be of some value in the treatment of metastatic renal cell carcinoma $(10,15,16)$, is unknown in the setting of gastrointestinal metastases.

Endoscopic nonsurgical therapeutic options in the face of biliary obstruction include percutaneous stenting (4) and standard ERCP, and sphincterotomy with stenting (6). Although a nonsurgical approach to metastatic disease may seem appealing, the patient may have a very favourable postsurgical outcome. The investigators from Johns Hopkins University reported long term survival ranging from 12 to 60 months after resection in $66 \%$ of their patients (7). Certainly with active gastrointestinal bleeding, such as our patient experienced, surgical resection seems to be definitive therapy unless the clinical circumstances dictate otherwise.

The interesting aspect of this case was the difficulty identifying a source of upper gastrointestinal bleeding in a patient with intermittent blood loss. The tumour - the source of bleeding - was only unequivocally diagnosed with the use of a side-viewing ERCP endoscope. Although conventional diagnostic imaging modalities such as small bowel followthrough and computed tomographic scan also would have visualized the tumour, these techniques may not be practical in an actively unstable bleeding patient, especially during nonworking hours. Venu and associates (3) have also commented on the necessity of a side-viewing endoscope to assess the ampulla of Vater as a possible source of upper gastrointestinal bleeding.

\section{CONCLUSIONS}

A periampullary tumour is a rare but reported presentation of a remote renal cell carcinoma. Our case and those reported in the literature suggest that most with periampullary metastases are males with originally left-sided primary cancers. The staging of the original renal cancer does not correlate with metastasis in this location, and a periampullary recurrence may present many years after nephrectomy. The sideviewing endoscope is an essential instrument in the diagnosis of these tumours, which should be considered in all cases of obscure upper gastrointestinal bleeding.

3. Venu RP, Rolny R, Geenen JE, et al. Ampullary tumor caused by metastatic renal cell carcinoma. Dig Dis Sci 1991;36:376-8.

4. Bolkier M, Ginesin Y, Moskovitz B, et al. Obstructive jaundice caused by metastatic renal cell carcinoma. Eur Urol 1991;19:87-8.

5. Robertson GS, Genier SL. Late presentation of metastatic renal cell 
carcinoma as a bleeding ampullary mass. Gastrointest Endosc 1990;36:304-6.

6. McKenna JI, Kozarek RA. Metastatic hypernephroma to the ampulla of Vater: An unusual cause of malabsorption diagnosed at endoscopic sphincterotomy. Am J Gastroenterol 1988;84:81-3.

7. Nakeeb A, Lillemoe KD, Cameron JL. The role of pancreaticoduodenectomy for locally recurrent or metastatic carcinoma to the periampullary region. J Am Coll Surg 1995;180:188-92.

8. Johnson NJ, Boyd EFS, Mills JG, Wood JR. Acute treatment of reflux esophagitis: A multicenter trial to compare $150 \mathrm{mg}$ ranitidine b.d. with $300 \mathrm{mg}$ ranitidine q.d.s. Aliment Pharmacol Ther 1989;3:259-66.

9. Motzer RJ, Bander NH, Nanus DM. Renal-cell carcinoma. N Engl J Med 1996;335:865-75.

10. Ritchie AWS, Chisholm GD. The natural history of renal carcinoma. Semin Oncol 1983;10:390-400.
11. Robson CJ, Churchill BM, Anderson W. The results of radical nephrectomy for renal cell carcinoma. J Urol 1969;101:297-301.

12. Kadakia SC, Parker A, Canales L. Metastatic tumors to the upper gastrointestinal tract: endoscopic experience. Am J Gastroenterol 1992;87:1418-23.

13. Sivak MV. Clinical and endoscopic aspects of tumors of the ampulla of Vater. Endoscopy 1988;20:211-7.

14. Yogoda A, Abi-Rached B, Petrylak D. Chemotherapy for advanced renal-cell carcinoma: 1983-93. Semin Oncol 1995;22:42-60.

15. Haarstad H, Jacobsen AB, Schjolseth SA, et al. Interferon-alpha, 5-FU and prednisone in metastatic renal cell carcinoma: a phase II study. Ann Oncol 1994;5:245-8.

16. Fosså SD, Martinelli G, Otto U, et al. Recombinant interferon alpha-2a with or without vinblastine in metastatic renal cell carcinoma: results of a European multi-center phase III study. Ann Oncol 1992;3:301-5. 


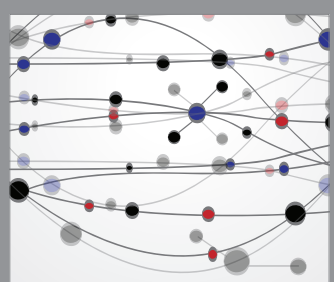

The Scientific World Journal
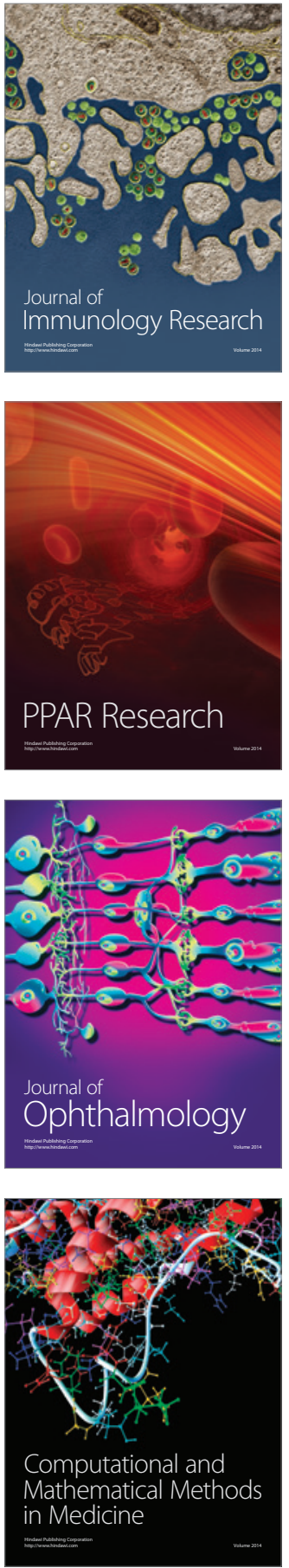

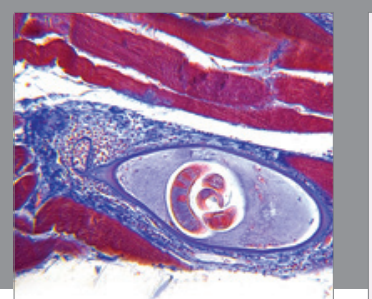

Gastroenterology Research and Practice

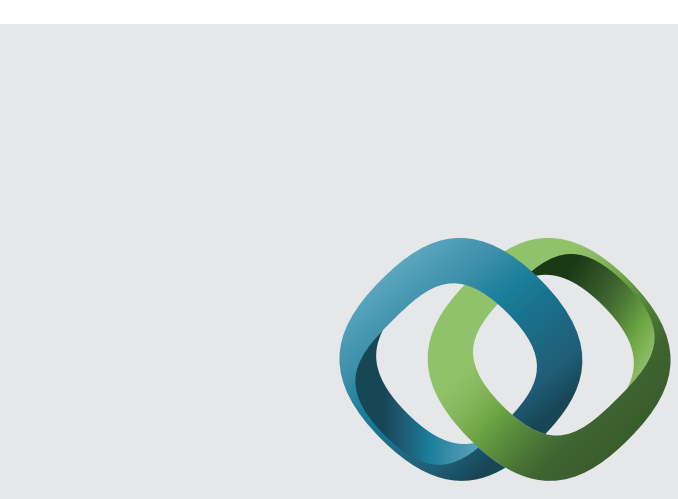

\section{Hindawi}

Submit your manuscripts at

http://www.hindawi.com
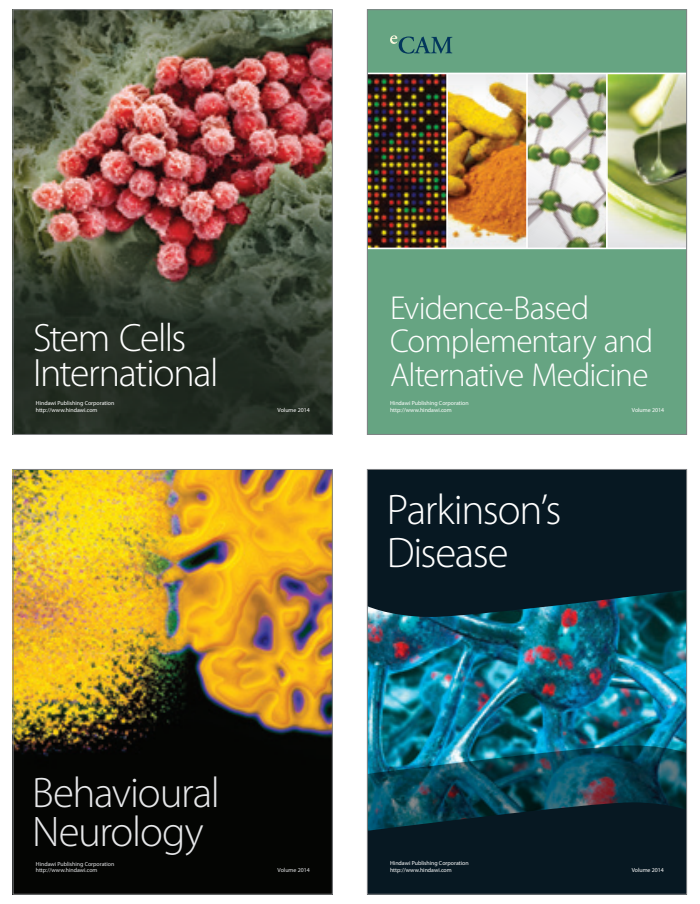
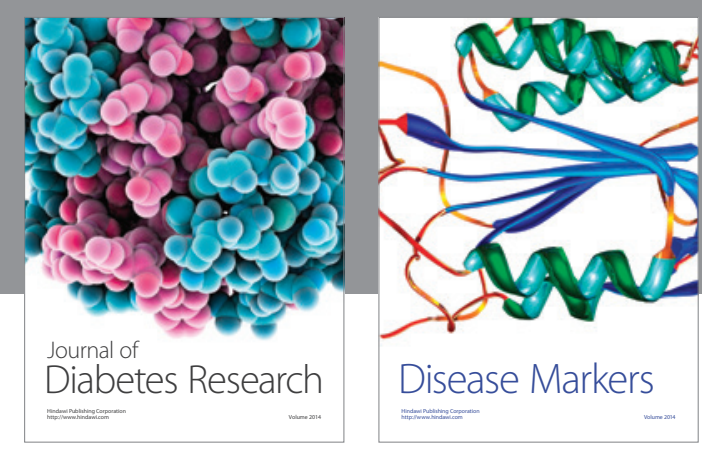

Disease Markers
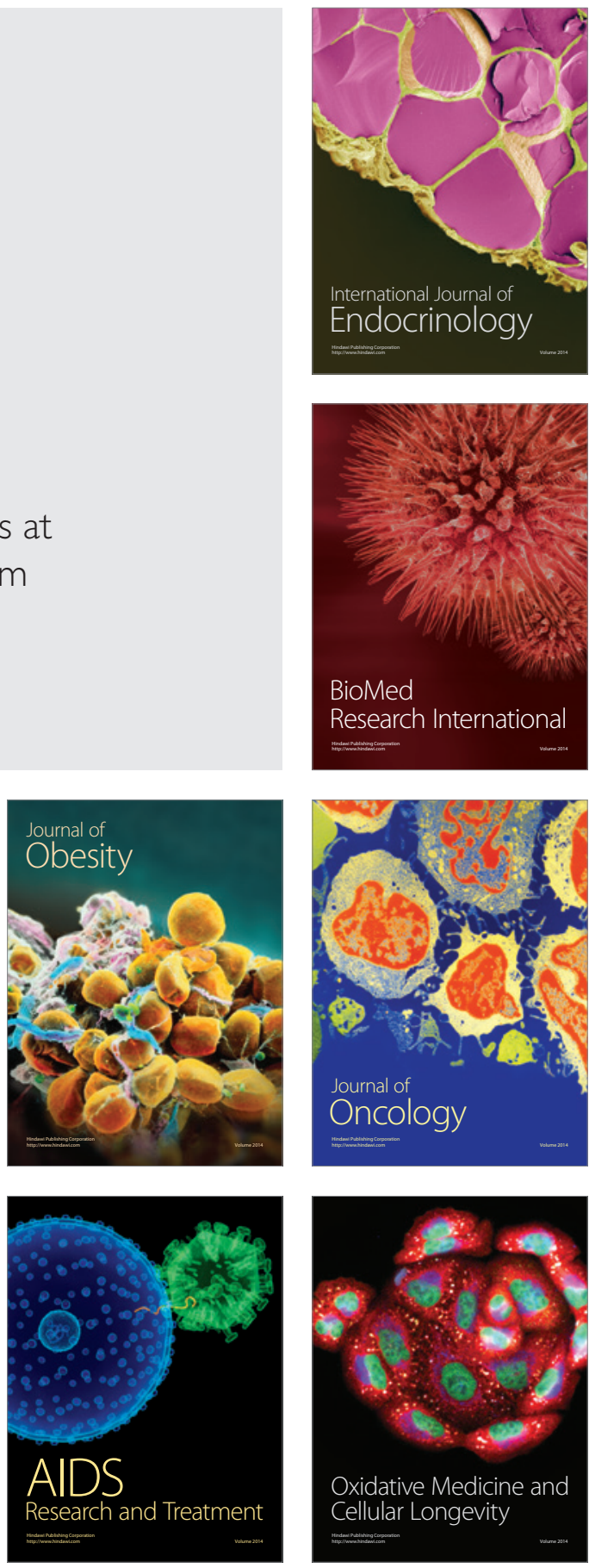